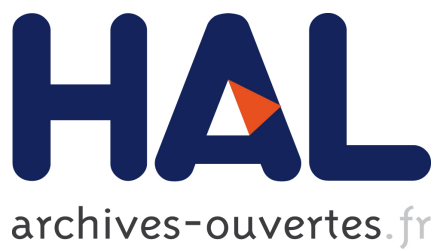

\title{
Emerging dance movements under ecological constraints in Contact Improvisation dancers with different background
}

\author{
C Torrents, J Coterón, A Ric, R Hristovski
}

\section{To cite this version:}

C Torrents, J Coterón, A Ric, R Hristovski. Emerging dance movements under ecological constraints in Contact Improvisation dancers with different background. CS-DC'15 World econference, Sep 2015, Tempe, United States. CS-DC'15 World e-conference. <hal-01291091>

\section{HAL Id: hal-01291091 \\ https://hal.archives-ouvertes.fr/hal-01291091}

Submitted on 20 Mar 2016

HAL is a multi-disciplinary open access archive for the deposit and dissemination of scientific research documents, whether they are published or not. The documents may come from teaching and research institutions in France or abroad, or from public or private research centers.
L'archive ouverte pluridisciplinaire HAL, est destinée au dépôt et à la diffusion de documents scientifiques de niveau recherche, publiés ou non, émanant des établissements d'enseignement et de recherche français ou étrangers, des laboratoires publics ou privés. 


\title{
Emerging dance movements under ecological constraints in Contact Improvisation dancers with different background \\ Torrents, C. ${ }^{1}$ Coterón, J. ${ }^{2}$ Ric, A. ${ }^{1}$ Hristovski, R. ${ }^{3}$ \\ ${ }^{1}$ INEFC-University of Lleida (Spain) \\ (carlotat@yahoo.com, angelric10@outlook.com) \\ ${ }^{2}$ Universidad Politécnica de Madrid (Spain) \\ (j.coteron@upm.es) \\ ${ }^{3}$ Sts. Cyril and Methodius University (Republic of Macedonia) \\ (robert_hristovski@yahoo.com)
}

\begin{abstract}
Contact improvisation dance generates different ways of moving and a varied use of motor creativity depending on the constraints acting on the system. The aim of this study was to analyse the softlyassembled dynamics and the emergency of different dance movements of different couples of improvisers with different background dancing under specific task constraints manipulations. One couple of contemporary dancers and one couple of novices were video-recorded while dancing with different constraints: 1) try to maintain both pelvis as close as possible and 2) try to maintain body contact but both pelvis as far as possible. Resulting trials were sequentially observed using an observational instrument and the data obtained were analysed using a soft-assembled hierarchy model analysis: a Principal Components Analysis (PCA), calculation of Hamming distances (HD) between binary vectors and the calculation of dynamic overlap order parameter $q$ to determine the structure of the potential landscape of the dancer and its dynamic properties. Results showed a higher exploratory behaviour when the system was constrained in a specific way, but also constraints forced the system to train specific techniques or movement patterns. Configurations were modified depending on the constraint in the couple of contemporary dancers, but the novices were less influenced.
\end{abstract}

Key words: creativity coordination dynamics. exploratory behavior

\section{Introduction}

Contact Improvisation is a form of dance improvisation which involves two bodies in contact. The improvisational characteristics of CI are such that the generation of movements is not based on fixed and standardized movements or techniques, since this dance form requires a body that responds to the physical exchange of weight and contact [1]. Theoretical approaches most used to explain creative behavior in dance are insufficient to explain how dancers create new configurations of movements during improvisation. Dance improvisation can be thought as a bank of emergent human movement forms and an expression of continuous exploration and discovery of idiosyncratic gestures, postures and actions supported by immediate affordances, i.e. opportunities for action.

Hristovski, Davids, Araújo and Button [2], in an empirical study based on the principles of coordination dynamics and using the framework of complex systems theories [3], showed how the manipulation of task and personal constraints may enable the emergence of innovative and functional tactical behaviors in athletes during sport performance. Under a specific mix of ecological constraints, performers in boxing generated certain behavioral states. It was observed that changing the set of task constraints led to spontaneous and novel behaviors, in this case, specific striking techniques that had not been practiced or taught before. These observations of the emergence of human tactical innovative behaviors are important from the perspective of Boden's [4] definition of 'transformational creativity', since they explain how, when manipulating constraints, a transformation within a neurobiological action system may be enabled without reference to abstract rule-governed behaviors. Specifically in dance, 
Torrents, Ric and Hristovski [5] studied couples of dancers improvising under different instructional constraints and observed that some of them had a significant effect on the type of configurations performed by the dancers, as well as on their creative behavior. Participants were all expert dancers, so the influence of the background in this phenomena remains unknown.

The aim of this study was to examine the effects that the manipulation of instructional task constraints has on the emergence of exploratory behavior in expert dancers and novices while improvising, and also to analyze the spontaneous emergence of specific movements in relation to the task constraints imposed.

\section{Methods}

One couple of contemporary dancers (one woman of 24 years old, $47 \mathrm{~kg}$ and $160 \mathrm{cms}$ and a man of 20 years old, $168 \mathrm{cms}$ and $64 \mathrm{kgs}$ ) and one couple of Physical Activities and Sports Science students without dance background (two men: $20 \pm 1$ years old; $71 \pm 7$ $\mathrm{kgs}$ and $175 \pm 7 \mathrm{cms}$ ) participated voluntarily in the study. Participants warmed up individually. They danced together in duets lasting 480 seconds, and in a limited space of $12 \times 12 \mathrm{~m}$. They danced under two different instructional constraints:

- Instructional constraint (IC) 1: When dancing, try to keep your pelvis as close as possible to your partner

- IC 2: When dancing, try to keep your pelvis as far away as possible from your partner

Four duets were video-recorded and video images were analyzed by two independent observers. The observers took into account the dance movements performed by each of the two dancers. Sequences of actions/postures were analyzed to determine their structural and dynamical characteristics. Action or posture and movements were defined on a coarse-grained scale. A total of 49 categories, corresponding to elementary movement/posture skill components (see Table 1), were taken into account. A value of 1 was ascribed to the active category and a value of 0 to the inactive one. This enabled the formation of a temporal 49x480 binary matrix with a time resolution of 1 second. Each 1-second window was defined as a 49-component binary vector (column) representing the full action configuration during the same time interval. It is important to note that each full action configuration ( $\operatorname{Lmax}=49)$ was composed of combinations of skill and movement of shorter length $(1<\mathrm{L}<\mathrm{Lmax})$, which in turn comprised elementary skill/movement categories, each with a length Lmin $=1$.

A principal component analysis (PCA) [6] was performed on the 49 (category) X 480 (time point) binary matrices defining movement/posture configurations. This was done with the aim of detecting the structure of the dancer's action landscape. The number of significant principal components was determined by identifying those that accounted for $\geq 80 \%$ of the explained variance.

The average dynamic overlap, $\langle\mathrm{qd}(\mathrm{t})\rangle$, was calculated as an average cosine autosimilarity of the overlaps between Lmax configurations with increasing time lag in order to determine the dynamic properties of a dancer's complex movement patterns [7]. This measure captures the average similarity of configurations at ever increasing time distances (i.e., time lags) from each other. Hence, it is capable of detecting the rate 
and breadth of exploratory behavior on different time scales. The average dynamic overlap was fitted by the following equation, which is derived for systems with an intricate hierarchical structure:

$$
\langle\mathrm{qd}(\mathrm{t})\rangle=(1-\mathrm{qstat}) \mathrm{t}-\alpha+\mathrm{qstat}
$$

where qstat is the asymptotic (i.e., stationary) value of the dynamic overlap, $t$ is the time lag, and $\alpha$ is the dynamic exponent. qstat detects the long-term exploratory breadth of the dancer, and $\alpha$ the rate of exploration.

In order to examine the coupling dynamics of the duets we conducted a crosscorrelation analysis of the Hamming distance time series. Hamming distance time series provide information about the size of individual reconfigurations in each time point, and hence, cross-correlating the time series tells us about the time profile and the strength of duet couplings.

\section{Results}

In general, the results from the component scores analysis show that certain movements attract the system and appear with a high frequency, while others are statistically rare and short-lived reconfigurations that constitute fluctuations (see fig. 1). These skills varied depending on the constraint and more clearly on the background of the dancers. First level PCA revealed 11 and 8 primary PCs for expert contemporary dancers in IC1, and 13 and 11 for IC2; Novice dancers obtained 5 or 6 primary PCs in both conditions, all results accounting for more than $80 \%$ of the total variance.

The highest level PC contained the dominant long-term persistent actions, such as: leading the partner using the foot-floor surface as support with bipedestrian locomotion and support of the partner with the upper limbs. These results are similar to that obtained in a previous study with expert dancers [5]. Nevertheless, when analysing the rest of the first level PCs, we were able to see that contemporary dancers were more influenced by the constraints imposed in the execution of specific skills. For instance, under pelvis-close constraint lifts were more time-persistent, although novices explored less coordination patterns. The PCs of the novices with pelvis-far constraint revealed that they dominantly used the support with the partner using upper limbs, while experts performed lots of combinations in all cases.

Figure 2 displays the average values obtained for all dancers and constraints of the stationary part of the dynamic overlap. The dynamic overlaps of pelvis-close constraints were always significantly higher than pelvis-far constraints (in both couples), while the values obtained by expert dancers were always significantly lower than amateurs (in both constraints). Hence, combined skill level and instructional constraints together revealed differences in the exploratory breadth of performers. It is interesting to notice that the observational instrument coupled to the measure of dynamic overlap is able to detect the differences in the exploratory breadth within expert and novice couples as well as between them. For example, N2 showed lower exploratory breadth than N1 performer in both, the pelvis-close and pelvis-far conditions. Similarly, E2 showed lower exploratory behaviour than E1 in both conditions too. 
Table 1. Observational instrument defined on a coarse-grained scale based on action or posture skills and movements [5]

\begin{tabular}{|c|c|}
\hline \multirow{6}{*}{$\begin{array}{l}\text { 1-6: Support stability skills } \\
\text { involving the floor: } \\
\text { Actions of stability or balance using } \\
\text { the floor that can be supported by... }\end{array}$} & Upper limbs (one or two) \\
\hline & Lower limbs (one or two) \\
\hline & Head \\
\hline & Pelvis \\
\hline & Torso \\
\hline & Back \\
\hline \multirow{6}{*}{$\begin{array}{l}\text { 7-12: Support stability over } \\
\text { a partner: } \\
\text { Actions of stability or balance } \\
\text { supported over the... of the partner }\end{array}$} & Upper limbs (one or two) \\
\hline & Lower limbs (one or two) \\
\hline & Head \\
\hline & Pelvis \\
\hline & Torso \\
\hline & Back \\
\hline \multirow{4}{*}{$\begin{array}{l}\text { 13-16: Axial stability skills: } \\
\text { Turns around the... }\end{array}$} & Longitudinal axis of the body \\
\hline & Horizontal transverse axis of the body \\
\hline & Horizontal anteroposterior axis of the body \\
\hline & A combination of axes \\
\hline \multicolumn{2}{|l|}{ 17: Jumping } \\
\hline \multicolumn{2}{|c|}{ 18: Being lifted or sustained by the partner } \\
\hline \multirow[t]{2}{*}{ 19-20: Level changing from... } & Middle to down or falling \\
\hline & Down to middle or rising from the floor \\
\hline \multirow{4}{*}{$\begin{array}{l}\text { 21-24: Locomotor skills } \\
\text { involving... }\end{array}$} & Walking \\
\hline & Movement on all fours \\
\hline & Rolling \\
\hline & Sliding \\
\hline \multicolumn{2}{|l|}{ 25: Receiving the partner } \\
\hline \multicolumn{2}{|l|}{ 26: Colliding with the partner } \\
\hline \multicolumn{2}{|l|}{ 27: Leading the partner } \\
\hline \multicolumn{2}{|c|}{ 28: Lifting or sustaining the partner } \\
\hline \multicolumn{2}{|c|}{ 29: Avoiding or escaping from the partner } \\
\hline \multirow{18}{*}{$\begin{array}{l}\text { 30-47: Positions or actions of the } \\
\text { different parts of the body: }\end{array}$} & One leg is bent \\
\hline & Both legs are bent \\
\hline & One leg is moving \\
\hline & Both legs are moving \\
\hline & One arm is bent \\
\hline & Both arms are bent \\
\hline & One arm is moving \\
\hline & Both arms are moving \\
\hline & One arm is relaxed, following gravity line \\
\hline & Both arms are relaxed \\
\hline & Body is almost aligned \\
\hline & Body is bent forwards \\
\hline & Body is bent backwards \\
\hline & Body is bent to the right \\
\hline & Body is bent to the left \\
\hline & Body is moving \\
\hline & Body is inverted (more than $45^{\circ}$ ) \\
\hline & Head is moving \\
\hline \multicolumn{2}{|c|}{ 48: There is a change in the direction of the movement } \\
\hline \multicolumn{2}{|c|}{ 49: There is a change in the global position of the body } \\
\hline
\end{tabular}




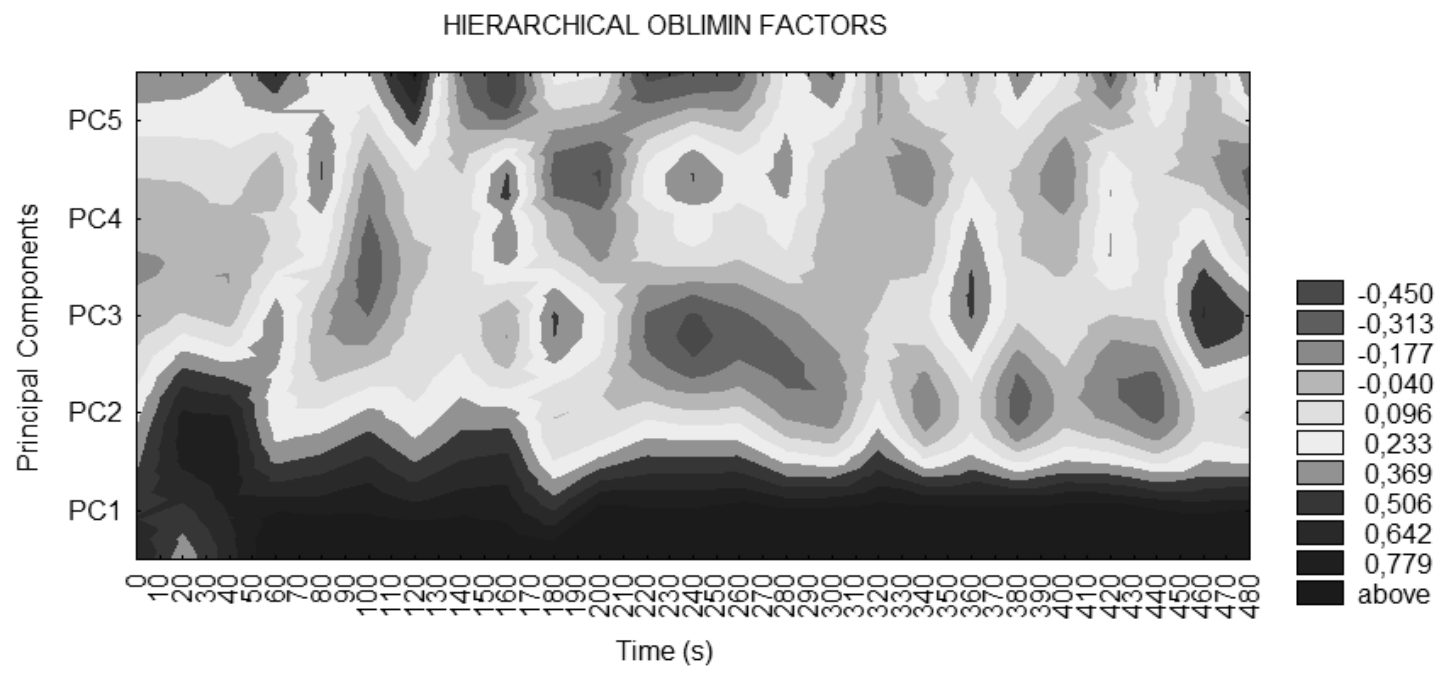

Fig. 1 Typical potential landscape of action configurations of one of the novice dancers. The first principal component appears with higher frequency compared with the rest.

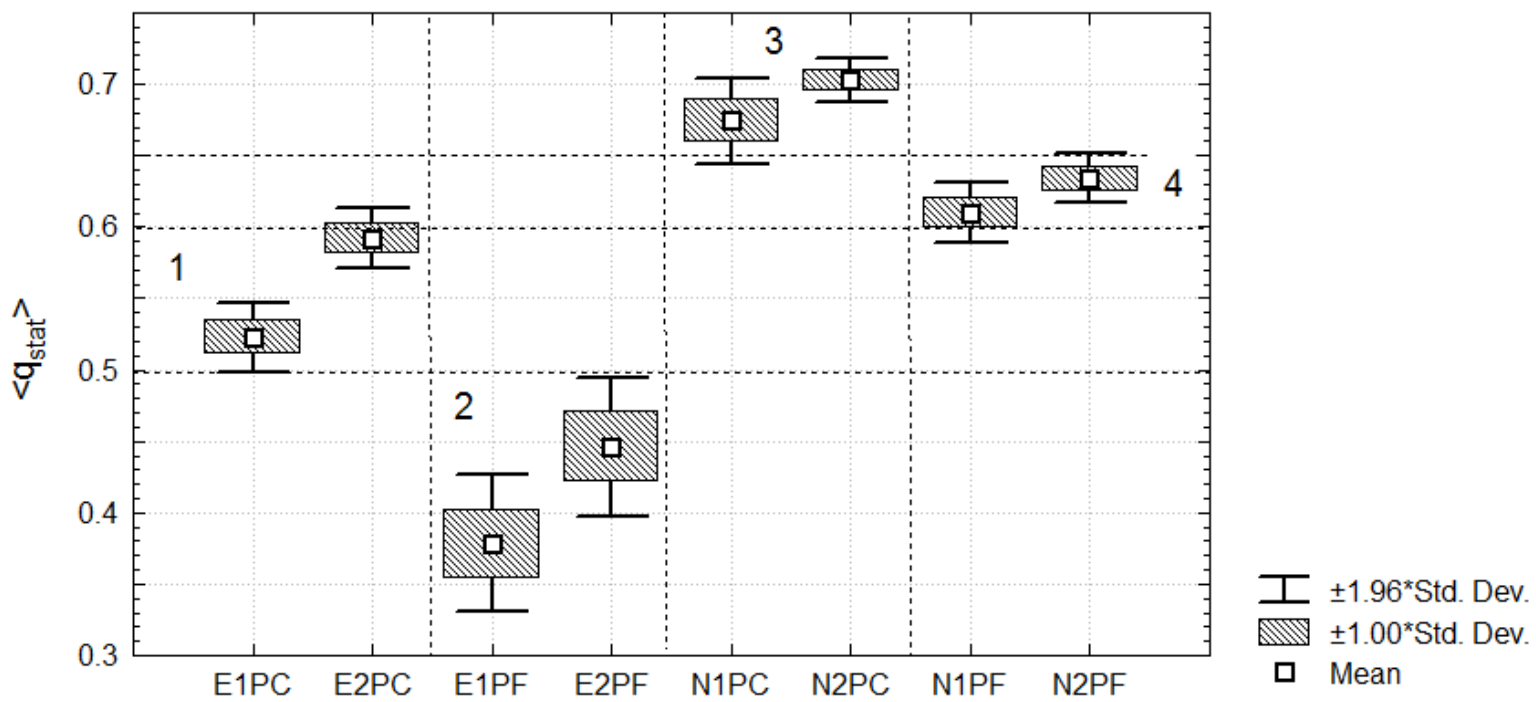

Fig. 2. The profiles of the stationary values of the dynamic overlap $\left\langle q_{\text {stat }}\right\rangle$ for expert E1 and $\mathrm{E} 2$ dancers and novice ( $\mathrm{N} 1$ and $\mathrm{N} 2)$ dancers, under 2 instructional constraints, pelvis-close (PC) and pelvis-far (PF).

The cross-correlation of Hamming distances time series showed consistently weak but significant lag 0 (synchronous reconfigurations) until lag 3 (leading-following reconfigurations) correlations in expert dancers under both ICs but just with pelvis far in novels. Changes in reconfiguration sequences illustrated the versatility of the strength and length of the temporal couplings between actions in expert dancers. However, it is suggested that ICs influenced coupling dynamics of novel dancers, as dancing with pelvis-close disrupted the couple to be adhered to synchronous and leading-following reconfigurations.

\section{Discussion}

Instructional constraints, as well as the level of the dancers, had a significant effect on the type of configurations performed by the dancers and on the exploratory breadth 
$\left(\left\langle q_{\text {stat }}\right\rangle\right)$. Dancing with IC1 constrained the emergence of some specific CI skills in the dancers with experience, and with IC2 constrained the emergence of other skills, but these instructional constraints were not enough to produce the emergence of those movement forms in novice dancers.

In terms of the exploratory behaviour all dancers produced a greater long-term exploratory breadth $\left(\left\langle q_{\text {stat }}\right\rangle\right)$ when dancing under pelvis-far constraints. For expert dancers, this constraint forced a different dance that they were used, as CI is usually danced with a lot of contact with the partner. For novices, dancing under PC constraint was really difficult. It created a very repeating behaviour based on stereotyped movements of social dances. These results point to a significant reduction of degrees of freedom when forcing the dancers to dance so close.

\section{References}

1. Albright, A.C.: Contact improvisation at twenty-five. In: Albright, B.C., Gere, D. (Eds.) Taken by Surprise. A Dance Improvisation Reader. Middletown, Wesleyan University Press (2003)

2. Hristovski, R., Davids, K., Araújo, D., Button, C.: How boxers decide to punch a target: emergent behavior in nonlinear dynamical movement systems, Journal of Sports Science and Medicine CSSI, 60-73 (2006)

3. Kelso, J.A.S.: Dynamic Patterns - The Self-Organisation of Brain and Behavior, Cambridge, MIT Press (1995)

4. Boden, M.A.: What is Creativity. In: M.A. Boden (Eds.). Dimensions of creativity. MIT Press (1996)

5. Torrents, C., Ric, A., Hristovski, R.: Creativity and emergence of specific dance movements using instructional constraints. Psychology of Aesthetics, Creativity and the Arts, 9, 65-74. (2015)

6. Westerhuis, J.A., Kourti, T., MacGregor, J.F.: Analysis of Multiblock and Hierarchical PCA and PLS Models. Journal of Chemometrics, 12, 301-321 (1998)

7. Hristovski, R., Davids, K., Araújo, D., Passos, P., Torrents, C., Aceski, A., Tufekcievski A.: Creativity in sport and dance: Ecological dynamics on a hierarchically soft-assembled perception-action landscape. In: K. Davids, R. Hristovski, D. Araújo, N. Balagué, C. Button, P. Passos (Eds.), Complex systems in sport (pp. 261-274) London: Routledge (2013)

\section{Scientific Validation}

This paper has been unanimously validated in a collaborative review mode with the following reviewers:

- $\quad$ Reviewer 1 : Christophe Schnitzler, University of Strasbourg

- $\quad$ Reviewer 2: Ludovic Seifert, University of Rouen 